OPEN ACCESS

Edited by:

Akber Datoo,

Independent Researcher, London,

United Kingdom

Reviewed by: Nadia C. Fabrizio,

Cefriel, Italy

Michele Marchesi,

University of Cagliari, Italy

*Correspondence:

Lan van Wassenaer

lan.vanwassenaer@wur.nl

Specialty section: This article was submitted to

Smart Contracts,

a section of the journal

Frontiers in Blockchain

Received: 13 January 2021 Accepted: 12 April 2021

Published: 29 April 2021

Citation:

van Wassenaer $L$, Verdouw $C$ and Wolfert S (2021) What Blockchain Are

We Talking About? An Analytical

Framework for Understanding

Blockchain Applications in Agriculture

and Food.

Front. Blockchain 4:653128

doi: 10.3389/fbloc.2021.653128

\section{What Blockchain Are We Talking About? An Analytical Framework for Understanding Blockchain Applications in Agriculture and Food}

\author{
Lan van Wassenaer ${ }^{1 *}$, Cor Verdouw ${ }^{2,3}$ and Sjaak Wolfert ${ }^{1}$ \\ ${ }^{1}$ Wageningen Economic Research, Wageningen, Netherlands, ${ }^{2}$ Information Technology Group, Wageningen University, \\ Wageningen, Netherlands, ${ }^{3}$ Mprise Agriware, Veenendaal, Netherlands
}

With the many promises it holds in addressing problems concerning information exchange and digital transactions in multi-actor processes, blockchain technology (BCT) has gained considerable traction in the agrifood sector. Governments, international organisations, private companies, consortia of public and private actors are launching various blockchain projects for improving transparency, traceability, and many other key issues in the agrifood sector. This has resulted in a large number of use cases. It is often unclear, however, what and how technical, social and economic aspects were considered in different usecases. Due to the novelty and elusiveness of the technology, there is no ready-to-use analytical framework or guideline yet for assessing its applicability and choosing the right technical and organisational setup. As a result, many stakeholders have to grope in the dark when designing and implementing their "blockchain application." Based on studies of use cases worldwide and experiences in organizing different blockchain pilots in the Netherlands, this paper seeks to address this problem by providing an overview of the choices to be made at three layers of a blockchain application: the ledger, the governance structure and the ecosystem. This can serve as a reference framework for understanding different blockchain applications and choosing key parameters for new use cases in the agrifood sector. It is expected that such demystification of the blockchain will contribute to more realistic and effective application of the technology to pressing problems in agriculture and food.

Keywords: blockchain application, blockchain governance, blockchain framework, blockchain ecosystem, agriculture and food

\section{INTRODUCTION}

Blockchain technology seems to follow the blueprint process for a technological hype as described by Gartner's hype cycle (Hawlitschek et al., 2020). The hype cycle distinguishes five phases of development for emerging technologies such as BCT: innovation trigger, the peak of inflated expectation, the through of disillusionment, the slope of enlightenment and eventually reaching the plateau of productivity.

At the moment, cryptocurrency applications of BCT have muddled through waves of disillusionment and seem to be gradually climbing up on the slope of enlightenment. Similar trends are observed for the application of BCT in agriculture although the awareness of the 


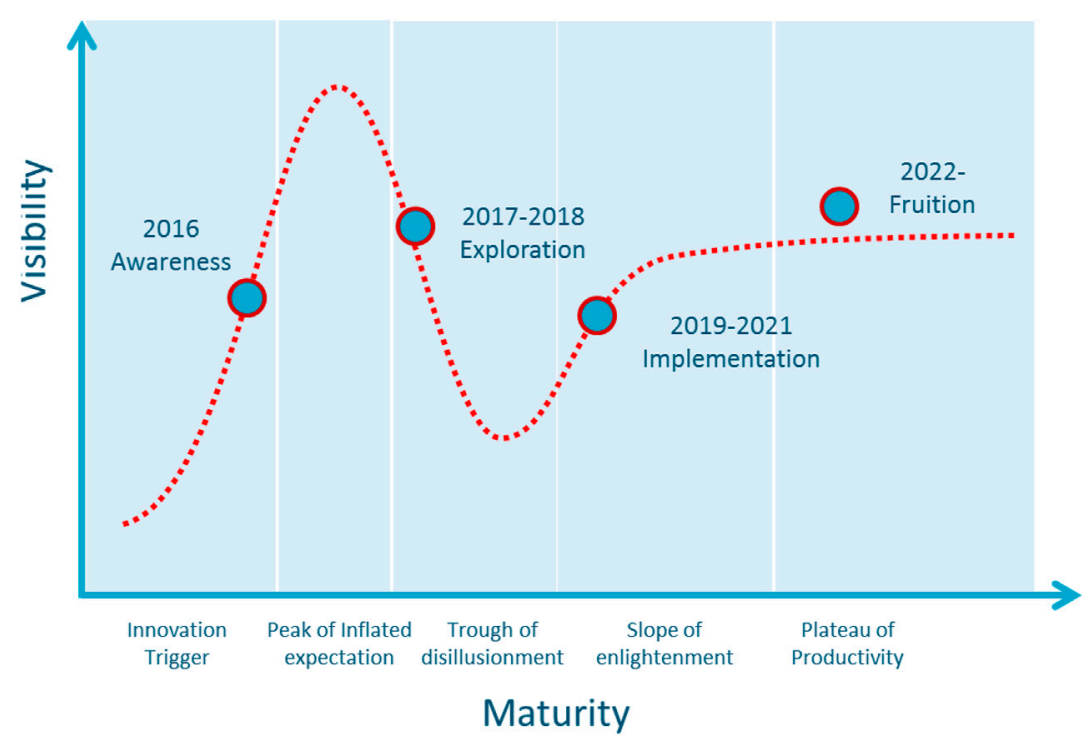

FIGURE 1 | The hype cycle of blockchain in agriculture and food (Source: van Wassenaer et al., 2021).

technology and the "peak of inflated expectation" have arrived later and were soon shadowed by the "disillusionment" of developments in cryptocurrencies. As indicated in Figure 1, the period 2017-2018 has been an important phase of exploration for the applications of blockchain in agri-food and increasingly more use cases are identified and implementation expected since 2019 (Ganne, 2018; Ge et al., 2017; Kamilaris et al., 2019; Motta et al., 2020).

BCT was considered of great relevance to the agri-food sector because agri-food transactions are fraught with information management problems that are known to affect food safety, quality and environmental sustainability (see e.g., Sylvester, 2019; Trienekens et al., 2012). However, the technology has also been surrounded by a great deal of exaggeration and hype resulting in misplaced expectations and misunderstandings. BCT is still in an early stage of development, with considerable potential for reallife commercial applications. Innovation in blockchain architectures, applications and business concepts is happening at a fast pace. The rapid but unpredictable direction of blockchain innovation makes it particularly hard for commercial organisations and government agencies to make strategic decisions on how to respond to BCT. The growing number of applications, however, makes it possible to study and understand different facets of the technology and enables realistic assessment of the potentials and challenges (Rana et al., 2021; Saurabh and Dey, 2021; Upadhyay, 2020).

The aim of this paper is to provide an analytical framework for understanding and comparing different blockchain applications and choosing key parameters for new use cases in the agrifood sector. In particular, our analysis has been conducted with the focus on the traceability and transparency of goods (food products and ornamental plants) in the agrifood supply chains. It is expected that such an analytical framework can help demystify blockchain application and contribute to more realistic and effective application of the technology to pressing problems in agriculture and food systems that requires collection actions.

\section{BLOCKCHAIN APPLICATION: A THREE-TIER VIEW}

Although often referred to as "the blockchain," BCT is not a single technology, but a combination of technologies that have a considerable history in computer science and in commercial applications (see e.g., Swan, 2016). Similarly, a blockchain application is a combination of different technical and organisational components at three layers:

- The distributed ledger;

- The governance structure for using the ledger;

- The ecosystem (actors and stakeholders involved in the blockchain application).

In the strict sense, blockchain refers only to the distributed ledger that consists of a series of data blocks linked to each other using cryptographic hashing functions to ensure its integrity and consistency. However, what is to be included in the data blocks and how new blocks are added to existing blocks depend on the governance of the ledger-the decision-making structure that sets the rules and protocols. This necessarily involves an ecosystem of human actors that translate their interests and power positions into arrangements and agreements. To understand the key aspects of blockchain application requires therefore a closer look at each of these three layers and how they relate to each other.

\section{The Distributed Ledger}

Distributed ledger refers to a type of database that is shared, replicated and synchronized among the members of 
TABLE 1 | A list of blockchain frameworks most used in agrifood.

\begin{tabular}{|c|c|c|c|c|c|c|c|c|}
\hline $\begin{array}{l}\text { Blockchain } \\
\text { framework }\end{array}$ & $\begin{array}{c}\text { Year } \\
\text { of } \\
\text { establishment }\end{array}$ & $\begin{array}{l}\text { Ledger } \\
\text { type }\end{array}$ & $\begin{array}{c}\text { Code } \\
\text { governance }\end{array}$ & Language & $\begin{array}{c}\text { Cryptocurrency/ } \\
\text { Tokens }\end{array}$ & $\begin{array}{l}\text { Consensus } \\
\text { mechanism }\end{array}$ & Pros & Cons \\
\hline Ethereum & 2013 & $\begin{array}{l}\text { Public or private; } \\
\text { permissionless } \\
\text { main net }\end{array}$ & $\begin{array}{l}\text { Ethereum } \\
\text { developers }\end{array}$ & $\begin{array}{l}\mathrm{C}++, \text { go, rust, } \\
\text { smart contracts } \\
\text { in solidity }\end{array}$ & $\begin{array}{l}\text { Ether }(E T H) \text {, not- } \\
\text { native tokens }\end{array}$ & $\begin{array}{l}\text { Proof of work, } \\
\text { proof of stake } \\
\text { ("casper") in } \\
\text { progress }\end{array}$ & $\begin{array}{l}\text { Popularity, } \\
\text { dApps }\end{array}$ & $\begin{array}{l}\text { Energy } \\
\text { consumption } \\
\text { (PoW), fluctuation } \\
\text { of ETC, not proven } \\
\text { scaleability and } \\
\text { security (PoS) }\end{array}$ \\
\hline $\begin{array}{l}\text { Hyperledger } \\
\text { fabric }\end{array}$ & 2015 & $\begin{array}{l}\text { Private, } \\
\text { permissioned }\end{array}$ & $\begin{array}{l}\text { The linux } \\
\text { foundation }\end{array}$ & $\begin{array}{l}\text { Go, chaincode } \\
\text { (smart contracts) } \\
\text { in go, javascript, } \\
\text { or java, SDKs in } \\
\text { Node.js, java, go, } \\
\text { REST and python }\end{array}$ & $\begin{array}{l}\text { Tokens via } \\
\text { chaincode }\end{array}$ & PBFT & $\begin{array}{l}\text { Enterprise- } \\
\text { ready }\end{array}$ & $\begin{array}{l}\text { Complex } \\
\text { architecture }\end{array}$ \\
\hline lota & 2016 & Public & $\begin{array}{l}\text { lota } \\
\text { foundation }\end{array}$ & Rust, go & Yes & $\begin{array}{l}\text { Tip selection } \\
\text { algorithm }\end{array}$ & Scalability & $\begin{array}{l}\text { Functions are } \\
\text { limited to loT }\end{array}$ \\
\hline MultiChain & 2015 & $\begin{array}{l}\text { Permissioned, } \\
\text { private }\end{array}$ & $\begin{array}{l}\text { Coin } \\
\text { Sciences }\end{array}$ & $\mathrm{C}++$ & None & $\begin{array}{l}\text { Roundrobin } \\
\text { schedule }\end{array}$ & $\begin{array}{l}\text { Enterprise, } \\
\text { open source }\end{array}$ & $\begin{array}{l}\text { Does not support } \\
\text { smart contracts }\end{array}$ \\
\hline Quorum & 2017 & Permissioned & $\begin{array}{l}\text { Quorum } \\
\text { community }\end{array}$ & GO, solidity & None & Raft, BFT & $\begin{array}{l}\text { Enhanced } \\
\text { transaction } \\
\text { and contract } \\
\text { privacy }\end{array}$ & $\begin{array}{l}\text { Native token not } \\
\text { possible }\end{array}$ \\
\hline
\end{tabular}

decentralized network (Mainelli and Smith, 2015; Swanson, 2015; Walport, 2016). Blockchain is a type of distributed ledger in which a series of data blocks are linked to each other using cryptographic hashing functions. In decentralized systems, a consensus mechanism is required to ensure data consistency between different nodes.

In general, the design of consensus mechanism should ensure the following (see e.g., Cachin and Vukolić, 2017; Carrara et al., 2020; Gramoli, 2020):

- Consistency: Consensus nodes eventually need to agree on the data;

- Timeliness: Consensus nodes should complete the data consensus in as short a time as possible;

- Security: It takes a huge cost to undermine consistency and cannot be easily attacked.

Theoretically, distributed ledger can use any algorithms that can meet the above requirements. Their performances may however differ in speed, security, and availability (Sayeed and Marco-Gisbert, 2019). It is therefore important to choose consensus algorithms that suit the purpose and meet the requirements of the application being developed.

At the level of the distributed ledger and consensus mechanisms, many choices already need to be made for software implementation. The major choices are reflected in so-called blockchain frameworks. A blockchain framework is a software solution that simplifies the development, deployment, and support of technically complex products. The frameworks usually contain the basic technologies and modules enabling developers to extend or add specific components. Blockchain frameworks help developers work faster and more efficiently and allow tailored choices due to their diversity. To illustrate this diversity, Table 1 provides an overview of blockchain frameworks most used in agrifood with short comments on the pros and cons. It should be noted that the list is not exhaustive, and the advantages and disadvantages can be judged very differently, depending on the benchmarks used and the perspectives of the evaluator.

\section{Governance Structure}

Governance of blockchain or blockchain governance is an important yet confusing aspect in blockchain application as the term is often loosely used by writers without a clear definition (Bohme et al., 2015; Reijers et al., 2016). The concept of governance itself also defies a universal definition. In different contexts, blockchain governance may consequently cover different aspects of blockchain organization. Notable efforts have however been made to provide consistent and operational frameworks to compare different blockchain systems (see e.g., van Pelt, 2019).

From a practical perspective, a governance structure describes decision-making both on the blockchain and off the blockchain. This includes the distribution of power to make and change the operating rules of the blockchain. In general, the governance structure for blockchain application consists of different configurations of the following key elements:

- Participation, the extent to which participation of the blockchain application requires permission;

- Access control, decisions with regard to who writes and reads a data block;

- The use of smart contracts, i.e., computerized transaction protocols;

- Code governance, open source, community development, etc. 


\section{Participation}

Participation can be 1) open: all actors have the right to participate in decision-making; 2) permissioned: a limited number of actors have the right to participate in decisionmaking. It should be noted that besides the right to participate, there are also requirements for participation with regard to IT facilities and basic knowledge and skills, (e.g. literacy). This may pose practical constraints on users who cannot meet these requirements and exacerbate existing gender and income inequalities, i.e., the "digital divide" (Hughes, 2017).

\section{Access Control}

This refers to the control of access to the ledger and related services. To control who reads and writes a block plays a vital role in every blockchain business solution.

Broadly, there are three types of access control: 1) private, only certain groups of users can have access to the blockchain; 2) public permissioned, anyone meets the criteria can have access to the blockchain; and 3) permissionless, no permission is needed to access the blockchain (Buterin, 2015; Gramoli, 2016).

\section{Smart Contracts}

Smart Contract can be defined as a piece of computerized transaction protocol that satisfies contractual conditions such as payment terms, confidentiality or enforcement, reduces exceptions and minimizes the need for trusted intermediaries. Smart Contract has received renewed attention in relation to blockchain due to its potential in automating transactions in a trustless network (Ante, 2020). It is generally acknowledged that smart contract has the potential of automating and simplifying business transactions and the audit trail of certification. Smart contracts allow to programmatically control the access and features available to users and as such can be used as a further level to implement governance.

\section{Code Governance}

After deciding which user can access the ledger to read and to write, each blockchain application needs to define the peer participation to the project that can be open, technical or alliance (Bohme et al., 2015; Nakamoto, 2008; Yermack, 2017). As a consequence, the code license can be open and accessible to everyone or closed (Drescher, 2017).

Different governance structures result in three different types of blockchain: public, private and hybrid blockchain (Niranjanamurthy et al., 2019). The selection of the blockchain type depends highly on the objectives of the blockchain project, what type of value is exchanged and the characteristics of the actors involved in the application. Before choosing the type of blockchain and its governance model, a more pertinent question to address is whether BCT is applicable as there are alternative systems (such as relational databases and document based webportals) for sharing data among different actors in the network. To this end, it is advisable to careful consider the applicability of BCT by going through a checklist that can be easily found on the internet (see also van Wassenaer et al., 2021).

\section{Blockchain Ecosystem}

Blockchain is increasingly viewed as a collaborative physical and business ecosystem involving different devices, users, investors, operators, and IT solution providers (including providers and developers of IT infrastructure, software platforms and applications) (Riasanow et al., 2018). The physical ecosystem consists of a network of nodes. Each node is a computer, server, or storage device of some sort. From a functional perspective, the blockchain can be seen as an ecosystem composed of a distributed database platform on top of which a number of interrelated software applications and services run. Each of these applications and services playing a separate but important role in the overall operation of the business. In short, the term "ecosystem" is an apt description of a blockchain application as it recognizes it as an amalgam of all the parts that make up the whole and how they interact with each other within the system and then with the outside world (Gujral, 2019).

A blockchain application typically involves a range of actors that form three circles of stakeholders (see e.g., the "onion models" in Alexander and Robertson, 2004): 1) those who fund and develop the application (the "core" stakeholders, including the funder and the IT solution provider); 2) those who directly interact with the application (the "containing" stakeholders, including those who indirectly use or provide information for the distributed ledger); and 3) the encompassing stakeholders who indirectly influence or are indirectly influenced by the application. The roles and activities of the same actor can differ in different use cases.

Ecosystem is one of the defining features of blockchain application. It is also one of the most challenging one to characterize and generalize. Typically, each use case has its own ecosystem with different actors and governance arrangements. A blockchain ecosystem comes into being through different value drivers and arrangements. Ecosystem functions such as funding and coordination are also performed by different actors. The viability of the ecosystem depends on the interplay of business model and governance model and the enabling environment in which the blockchain application takes place.

\section{UNDERSTANDING BLOCKCHAIN APPLICATIONS IN AGRICULTURE AND FOOD The Use of Blockchain in Agriculture and Food}

As observed by many authors (Antonucci et al., 2019; Bolt, 2019; Casino et al., 2018; Rana et al., 2021; Saurabh and Dey, 2021), the list of blockchain use cases is steadily growing in agriculture and food. Our framework is built upon studies of these use cases as well as our own experiences in developing various use cases. These applications address four main themes in agriculture and food: 1) supply chain management, this concerns the transparency and traceability of food chains; 2) farmer-centric, this concerns farmers' income, livelihood and access to financial markets and services; 3 ) environment-centric, this concerns the impact of food systems on the environment and climate change 


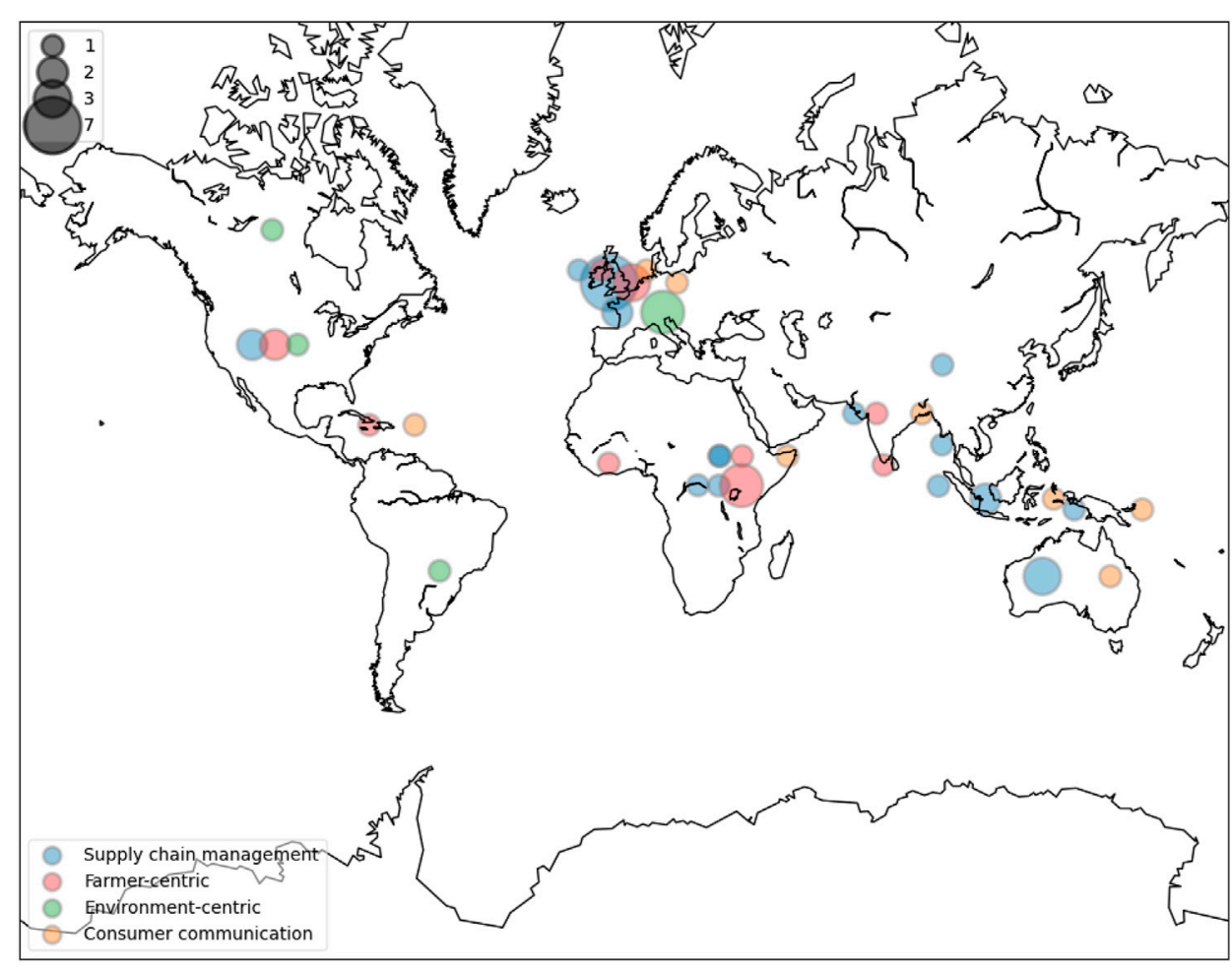

FIGURE 2 | Overview of the application themes and geographical distribution of the investigated use cases (updated in October 2020 and data visualisation by Philippe Debie). The sizes of the circles correspond to the number of use cases studied and the position of the circles showing the location of the headquarters of the leading actors in the ecosystem.

adaptation and mitigation; and 4) consumer communication, this concerns providing consumers with reliable information about the origin, provenance and quality of agrifood products. The large number of globally known use cases in agriculture and food suggests a high level of awareness of the technology in the sector. For the purpose of the present study we identified 38 use cases that have at least developed a Proof-of-Concept (PoC) application (see Supplementary Material for an overview of the use cases in which we present the main features of these use cases, including the use of tokens). In terms of blockchain frameworks, Ethereum is no doubt the most popular one and many use cases make use of non-native tokens based on Ether and smart contracts, to raise funds to finance the project (Kamilaris et al., 2021). Among use cases using permissioned blockchains, Hyperledger Fabric is the most used framework. Although Hyperledger Besu is often discussed (see e.g.,Vadgama and Tasca, 2021), we have not identified well-documented use case in agrifood using the framework.

Figure 2 visualizes the trend in the application themes and the geographical distribution of these use cases.

\section{The Value Drivers of Blockchain Use Cases: Governance and Business Benefits}

In general, the drivers for applying BCT in agriculture and food can be grouped into two categories: 1) addressing the lack of trust;
2) improving value creation. Topics in the first category typically include transparency, traceability and the integrity of information. In the second category, the focus is on improving value distribution or creation with improved information sharing.

For the first category, the foundation is the distributed ledger that ensures immutable records of identities, ownerships and transactions. For the second category, the true value driver is new governance arrangements and a conducive ecosystem that enables collaboration and fosters innovation. The governance benefits of the blockchain include disintermediation, therefore improved access to finance and less risk and transaction costs.

\section{Enabling Environment for the Blockchain Ecosystem}

Although the ecosystems for different blockchain use cases came into being through different paths, some patterns can be observed with regard to the governance model and the role of actors. Most use cases are initially funded by private funds (by private companies, private investors or crowdfunding through ICO), with the support of public actors in the form of grants, awards and supporting services. Many projects started as innovative ideas at hackathons or similar events. The initiators are mostly private actors in the value chain, with actors from the public sector mostly playing supported roles. Actors in the public sector are NGOs, standardization organisations and governments. 
To obtain more insight into the enabling environment and potential hurdles for blockchain applications, the PESTEL, (i.e. Political, Economic, Social, Technological, Environmental and Legal) framework can be used to identify relevant factors (Johnson et al., 2017). This include understanding the institutional framework policies, strategies and laws (including incentives) favoring or hindering the development and adoption of blockchain applications as well as economic, social, technological and environmental conditions that were conducive or prohibitive to the use cases.

Overall, the enabling institutional framework consists of favourable national and international policies toward digital solutions in terms of strategies and instruments (subsidy, grants and availability of land) and supportive governmental organisations. Economically, the rising popularity of platform financing appears to be the major pulling factor, while internet, digital platforms and IT solutions (fintech) provide the technological push and support. Interoperability across different blockchain platforms and with existing systems has been considered a major challenge to the scalability of blockchain applications (Yadav and Singh, 2019). From a social perspective, the applications thrive on ethical concerns for inclusiveness, transparency and accountability in agricultural value chains. NGOs are playing a prominent role in empowering smallholders. On the shadow side, concerns for privacy, security and energy consumption may create resistance to blockchain applications.

\section{Application of the Analytic Framework to the Use Case}

The investigated use cases demonstrate the multidimensionality of blockchain application at all three layers. To illustrate the use of the analytical framework, the use case Flori-Chain is described below.

\section{General Context of the Flori-Chain}

Flori-Chain, as the name suggests, is an application in the floriculture supply chain. The use case is developed in the Netherlands within the project 'Blockchain for automated compliance ${ }^{1}$. Sustainability compliance is a crucial issue in Dutch agriculture, not only in food but also in the production of flowers and plants. There are stringent regulations for example concerning pesticides usage. Moreover, retailers impose additional requirements and demand for different sustainability certificates. So far, in the floricultural sector compliance information is provided by individual organisations. A supply chain system for sustainability traceability and trusted compliance information is still lacking. As a consequence, it is very time-consuming and inefficient for supply chain companies to prove that their products are free of particular pesticides and to provide evidence for compliance to legal and market requirements. The Flori-Chain use case

${ }^{1}$ See more at https://topsectortu.nl/nl/blockchain-automated-complianceagrifood-chains-through-blockchain investigates the opportunities of Blockchain to overcome this situation.

Flori-Chain first focuses on sharing plant protection information within the Dutch floricultural chain. It has developed a PoC application to make transparent, per lot or batch, what was sprayed and when along the supply chain, whether the substances used were appropriate and permitted, and which certificate applied. The pre-requisite is that producers accurately register the relevant crop protection data in their Enterprise Resource Planning (ERP) systems.

\section{Flori-Chain Distributed Ledger}

The use case Flori-Chain is built upon Hyperledger Fabric in which smart contracts are known as Chaincode. Hyperledger Fabric is one of the most popular frameworks for permissioned blockchain. Flori-Chain uses smart contracts to manage access to the system and pre-validation of data. Furthermore, it includes smart contracts that check: i) whether the product code complies to the Floricode industry standards; ii) whether the pesticide is authorized by the Dutch Board for the Authorization of Plant Protection Products and Biocides (Ctgb); and iii) whether the use of a pesticide is permitted by a particular retailer (not listed on a company-specific blacklist).

\section{Flori-Chain Governance Structure}

The use case currently has a private governance structure. The decision-making participants in the $\mathrm{PoC}$ are limited to the companies of the supply chain involved, i.e., a producer of young plants (Plantise), a grower of pot plants (Addenda) and the flower auction Royal FloraHolland. All use case participants have access to the data, including the software developers, researchers and standardization body involved. For real-life usage, it is envisioned to extend participation to the majority of the (Dutch) pot plant sector, but participation will remain permissioned. Access control will remain private for supply chain data, but open for basic traceability data that are relevant for consumers. The code governance is currently alliance-based, managed by the project team. Furthermore, smart contracts are applied to check compliance of applied pesticides with the Floricode standards, the legal pesticide regulations of Ctgb and the requirements of particular retailers (see also previous section).

\section{Flori-Chain Ecosystem}

At the core of the Flori-Chain ecosystem is the Public Private Partnership (PPP) in the research project "Blockchain for Automated Compliance." The project is co-financed by the Dutch Ministry of Agriculture, Nature and Food Quality and private partners from the horticultural supply chain. Indirect users of the blockchain application include certification bodies and consumers that can verify the use of pesticide on ornamental plants. In the wider environment, the Ctgb is consulted on the use of the database and prescriptions. It is of crucial importance for the future success of the Flori-Chain that the ecosystem be extended to the majority of companies that are active in the pot plant sector, including: i) producers (about 1800 in total), ii) logistic service providers such as transporters, iii) auctions, iv) wholesalers, exporters and importers (about 1200 in total), different outlet 
channels including florists, supermarkets, garden and Do-It-Yourself (DIY) centers and webshops, and v) indirect actors such as authorities, pesticide residue labs, software vendors, advisors and investors (Salvini et al., 2020). For this reason, organisations with a central role in the supply chain are involved, especially Royal FloraHolland (the world's biggest flower auction) and Floricode (industry standardization body), and an important part of the project is dedicated to prepare for scaling-up, including dissemination and promotion activities.

\section{DISCUSSION}

BCT is still evolving. New blockchain frameworks and platforms continue to emerge as the popularity of some existing ones began to wane. Along with the high level of awareness of BCT, there is also a high level of confusion of what the technology is and entails. It is expected that this paper helps demystify blockchain application and contribute to more realistic and effective application of the technology to pressing problems in agriculture and food where collective actions are needed.

From this perspective, the role of public actors is crucial. In addition to the enabling environment, it is also important to look at the uncertainties and challenges for different parties to step in the blockchain projects. For initiators and operators of blockchain applications, the main challenge is how to acquire sufficient funding and technological resources for initial development and operations. Once the project is up and running, the major challenge is to attract investment and sufficiently large number of users for scaling up. For investors, the main challenge was the complexity and evolving nature of the technology which makes the success and return on investment uncertain.

The complexity of the technology and the lack of empirical evidence on the effectiveness and added value of blockchain applications constitute a major challenge for public actors, non-profit private actors or impact investors to engage or invest in blockchain projects. For regulators and public sector actors, the challenge is how to set the regulatory framework and safeguards without impeding innovation.

The simplicity of the proposed analytic framework can help stakeholders for a first assessment of the applicability and suitability of BCT. As such, the framework also has its limitations as many elements have not been included. For practical applications, for example, the framework should

\section{REFERENCES}

Alexander, I., and Robertson, S. (2004). Requirements - Understanding Project Sociology by Modeling Stakeholders. IEEE Softw. 21 (1), 23-27. doi:10.1109/ms. 2004.1259199

Ante, L. (2020). Smart contracts on the blockchain - A bibliometric analysis and review. Telematics and Informatics 57, 101519. doi:10.1016/j.tele.2020. 101519

Antonucci, F., Figorilli, S., Costa, C., Pallottino, F., Raso, L., and Menesatti, P. (2019). A Review on Blockchain Applications in the Agri-food Sector. J. Sci. Food Agric. 99 (14), 6129-6138. doi:10.1002/jsfa.9912 include considerations on scalability, performances, cost sustainability, security and privacy issues.

The ongoing COVID-19 pandemic has created both challenges and opportunities for blockchain applications in agriculture and food. On the one hand, many blockchain projects have encountered delay in fundraizing and development. On the other hand, data-driven solutions feature strongly in various response and recovery programmes of national and international organizations, which may further advance the development and adoption of blockchain applications. Against this background, it is even more important for policy makers and public actors to have a clear understanding of the technology and select the right parameters for blockchain applications in the agrifood sector.

\section{DATA AVAILABILITY STATEMENT}

The original contributions presented in the study are included in the article/Supplementary Material, further inquiries can be directed to the corresponding author.

\section{AUTHOR CONTRIBUTIONS}

LW conceptualized the framework for the paper, collected the data, and drafted the paper. CV contributed to the framework and drafted the description of the use case and discussion. SW provided input for the analysis of the use cases and helped to draft the paper and review the text.

\section{FUNDING}

This research is financed by the Dutch Ministry of Agriculture, Nature and Food Quality in the research program "Blockchain for agrifood" (project 228230042 BO-43.011.06-011) and the Topsector 'Tuinbouw \& Uitgangsmaterialen' (Project TU18125).

\section{SUPPLEMENTARY MATERIAL}

The Supplementary Material for this article can be found online at: https://www.frontiersin.org/articles/10.3389/fbloc.2021.653128/ full\#supplementary-material

Böhme, R., Christin, N., Edelman, B., and Moore, T. (2015). Bitcoin: Economics, Technology, and Governance. J. Econ. Perspect. 29 (2), 213-238. doi:10.1257/jep.29.2.213 Bolt, J. (2019). 'Financial Resilience of Kenyan Smallholders Affected by Climate Change, and the Potential for Blockchain technology.'. CCAFS, Available at: https://edepot.wur.nl/472583.

Buterin, V. (2015). "On Public and Private Blockchains," in Ethereum BLog, Vitalik Buterin. Editor V. Buterin, Available at: https://blog.ethereum.org/2015/08/07/ on-public-and-private-blockchains/.

Cachin, C., and Vukolić, M. (2017). 'Blockchain Consensus Protocols in the wild.' arXiv preprint arXiv:1707.01873. doi:10.1109/edcc.2017.36

Carrara, G. R., Burle, L. M., Medeiros, D. S. V., de Albuquerque, C. V. N., and Mattos, D. M. F. (2020). Consistency, availability, and partition tolerance in 
blockchain: a survey on the consensus mechanism over peer-to-peer networking. Ann. Telecommun, 75, 163-174. doi:10.1007/s12243-020-00751-w

Casino, F., Dasaklis, T. K., and Patsakis, C. (2019). A systematic literature review of blockchain-based applications: Current status, classification and open issues. Telematics and Informatics, 36, 55. doi:10.1016/j.tele.2018. 11.006

Drescher, D. (2017). Blockchain Basics. 1 Ed. Frankfurt Am Main. Germany: Apress. doi:10.1007/978-1-4842-2604-9

Ganne, E. (2018). Can Blockchain Revolutionize International Trade?. World Trade Organization. Available at:https://www.wto.org/english/res_e/booksp_ e/blockchainrev18_e.pdf.

Ge, L., Brewster, C., Spek, J., Smeenk, A., Top, J., Diepen, F. v., et al. (2017). Blockchain for Agriculture and Food: Findings from the Pilot Study. Wageningen: Wageningen Economic Research. doi:10.18174/426747

Gramoli, V. (2016). On the Danger of Private Blockchains, Available at: Https:// www.zurich.ibm.com/dccl/papers/gramoli_dccl.pdf.

Gramoli, V. (2020). From Blockchain Consensus Back to Byzantine Consensus. Future Generat. Comput. Syst. 107, 760-769. doi:10.1016/j.future.2017.09.023

Gujral, P. (2019). What Ecosystems Are in Blockchains? Blog: Available at:https://www. snowball.money/post/what-ecosystems-are-in-blockchains. doi:10.3386/w26182

Hawlitschek, F., Notheisen, B., and Teubner, T. (2020). A 2020 Perspective on "The Limits of Trust-free Systems: A Literature Review on Blockchain Technology and Trust in the Sharing Economy". Electron. Commer. Res. Appl. 40, 100935. doi:10.1016/j.elerap.2020.100935

Hughes, K. (2017). Blockchain, the Greater Good, and Human and Civil Rights. Metaphilosophy 48 (5), 654-665. doi:10.1111/meta.12271

Johnson, G., Whittington, R., Scholes, K., Angwin, D. N., and Regnér, P. (2017). Exploring Strategy. London: Pearson.

Kamilaris, A., Cole, I. R., and Prenafeta-Boldú, F. X. (2021). Blockchain in Agriculture. Elsevier, 247-284. doi:10.1016/b978-0-12-821470-1.00003-3

Kamilaris, A., Fonts, A., and Prenafeta-Boldú, F. X. (2019). The Rise of Blockchain Technology in Agriculture and Food Supply Chains. Trends Food Sci. Technol. 91, 640-652. doi:10.1016/j.tifs.2019.07.034

Mainelli, M., and Smith, M. (2015). 'Sharing Ledgers for Sharing Economies: an Exploration of Mutual Distributed Ledgers (Aka Blockchain technology)'. The Journal of Financial Perspectives 3 (3), 38-69.

Motta, G. A., Tekinerdogan, B., and Athanasiadis, I. N. (2020). 'Blockchain Applications in the Agri-Food Domain: The First Wave.'. Frontiers in Blockchain 3, 6. doi:10.3389/blockchain.2020.00006

Nakamoto, S. (2008). 'Bitcoin: A Peer-To-Peer Electronic Cash System.'. Available at:www.bitcoin.org.

Niranjanamurthy, M., Nithya, B., and Jagannatha, S. (2019). 'Analysis of Blockchain Technology: Pros, Cons and SWOT.'. Cluster Comput. 22 (6), 14743-14757. doi:10.1007/s10586-018-2387-5

Rana, R. L., Tricase, C., and De Cesare, L. (2021). 'Blockchain Technology for a Sustainable Agri-Food Supply chain.'. Br. Food J. doi:10.1108/bfj-09-20200832

Reijers, W., O’Brolcháin, F., and Haynes, P. (2016). Governance in Blockchain Technologies \& Social Contract Theories. Ledge 1, 134-151. doi:10.5195/ledger. 2016.62

Riasanow, T., Burckhardt, F., Soto Setzke, D., Böhm, M., and Krcmar, H. (2018). 'The Generic Blockchain Ecosystem and its Strategic Implications.' Available at: https://www.researchgate.net/publication/325677489.

Salvini, G., Hofstede, G. J., Verdouw, C. N., Rijswijk, K., and Klerkx, L. (2020). Enhancing Digital Transformation towards Virtual Supply Chains: a
Simulation Game for Dutch Floriculture. Prod. Plann. Contr., 1-18. doi:10. 1080/09537287.2020.1858361

Saurabh, S., and Dey, K. (2021). Blockchain Technology Adoption, Architecture, and Sustainable Agri-Food Supply Chains. J. Clean. Prod. 284, 124731. doi:10. 1016/j.jclepro.2020.124731

Sayeed, S., and Marco-Gisbert, H. (2019). 'Assessing Blockchain Consensus and Security Mechanisms against the 51\% attack.'. Appl. Sci. 9 (9), 1788.

Swan, M. (2016). "Blockchain Temporality: Smart Contract Time Specifiability with Blocktime," in Cham, Springer. Editors J. J. Alferes, L. Bertossi, G. Governatori, P. Fodor, and D. Roman, 184-196. doi:10.1007/978-3-31942019-6_12

Swanson, T. (2015). 'Consensus-as-a-service: a Brief Report on the Emergence of Permissioned, Distributed Ledger systems.'. Report, available online, Apr. doi:10.2172/1227165

Sylvester, G. (2019). E-agriculture in Action: Blockchain for Agriculture: Opportunities and Challenges: International Telecommunication Union, Available at: http://www.fao.org/3/ca2906en/CA2906EN.pdf.

Trienekens, J. H., Wognum, P. M., Beulens, A. J. M., and van der Vorst, J. G. A. J. (2012). Transparency in Complex Dynamic Food Supply Chains. Adv. Eng. Inf. 26 (1), 55-65. doi:10.1016/j.aei.2011.07.007

Upadhyay, N. (2020). Demystifying Blockchain: A Critical Analysis of Challenges, Applications and Opportunities. Int. J. Inf. Manag. 54, 102120. doi:10.1016/j. ijinfomgt.2020.102120

Vadgama, N., and Tasca, P. (2021). 'An Analysis of Blockchain Adoption in Supply Chains between 2010 and 2020.'. Frontiers in Blockchain 4, 8. doi:10.3389/fbloc. 2021.610476

van Pelt, R. (2019). "Blockchain Governance: A Framework for Analysis and Comparison." Faculty of Science, MS thesis. Utrecht: Univerity of Utrecht, Available at: https://dspace.library.uu.nl/bitstream/handle/1874/381894/Thesis_ RLvanPelt_Final.pdf? sequence=18isAllowed=y.

van Wassenaer, L., van Hilten, M., van Asseldonk, M., and van Ingen, E. (2021). 'Applying Blockchain to Climate Action in Agriculture: State of Play and Outlook: Background paper.'. Rome/Wageningen, FAO and WUR,. doi:10. $18174 / 532926$

Walport, M. (2016). 'Distributed Ledger Technology: beyond Block chain.'. UK Government Office for Science, Available at: https://www.gov.uk/government/ publications/distributed-ledger-technology-blackett-review.

Yadav, V. S., and Singh, A. (2019). A Systematic Literature Review of Blockchain Technology in Agriculture, pp. 973-981.

Yermack, D. (2017). 'Corporate Governance and Blockchains*.. Rev. Finance 21 (1), 7-31.

Conflict of Interest: CV was employed by Mprise Agriware.

The remaining authors declare that the research was conducted in the absence of any commercial or financial relationships that could be construed as a potential conflict of interest.

Copyright $\odot 2021$ van Wassenaer, Verdouw and Wolfert. This is an open-access article distributed under the terms of the Creative Commons Attribution License (CC $B Y)$. The use, distribution or reproduction in other forums is permitted, provided the original author(s) and the copyright owner(s) are credited and that the original publication in this journal is cited, in accordance with accepted academic practice. No use, distribution or reproduction is permitted which does not comply with these terms. 